Review

\title{
Lubricants for Metal Belt Continuously Variable Transmissions
}

\section{Keiichi Narita}

Lubricants Research Laboratory, Idemitsu Kosan Co. Ltd., 24-4 Anesakikaigan, Ichihara-shi, Chiba, 299-0107, Japan; E-Mail: keiichi.narita@idemitsu.com; Tel.: +81-436-61-2505;

Fax: +81-436-61-2017

Received: 4 December 2013; in revised form: 9 January 2014 / Accepted: 10 January 2014 /

Published: 25 February 2014

\begin{abstract}
This paper reviews the effects of lubricant additives and base stock used in metal belt continuously variable transmissions (CVT) fluids on the CVT transmission torque capacity. Additive formulation composed of phosphorus anti-wear agent, calcium detergent, and dispersant improved the friction coefficient between the metals. The analysis on the post-test surface suggests that the friction behavior strongly depends on the local morphology of the tribofilms derived from lubricant additives. Examining the effect of base stock on the torque capacity in actual belt CVTs revealed that SN (synthetic naphthene) exhibited $10 \%$ higher torque capacity than that of PAO (polyalphaolefin). It is believed that the difference in the torque capacity is due to the difference in the oil-film shearing force generated by the relative sliding between the belt and pulley.
\end{abstract}

Keywords: belt CVT; torque capacity; lubricant additives; base stock; boundary lubrication; surface analysis

\section{Introduction}

There are two types of transmission used in automobiles: automatic and manual. Automatic transmissions (ATs) occupied most market share of all transmission installed in passenger cars in USA and Japan [1]. In particular, there is an increasing number of cars that are equipped with continuously variable transmissions (CVTs), which shift speed ratios continuously without the use of stepped gears. The reason for this increase is that CVTs achieve better fuel efficiency than stepped ATs.

Figure 1 shows the type of CVTs, which is classified according to the mechanism that transmits the power. CVTs are divided into a metal push-belt, a chain belt, and a traction drive type. The metal push-belt type was firstly introduced for practical use in 1987 within 1-liter cars. Since that time the 
number of cars with metal push-belt CVTs has steadily increased each year, and currently there are even cars with an engine displacement of more than 3 liters that have been released. In Europe, chain belt CVTs are used in large size cars with a torque exceeding $400 \mathrm{~N} \cdot \mathrm{m}$. Chain CVTs have been on the market in Japan since 2010.

Figure 1. Type of continuously variable transmissions (CVTs).

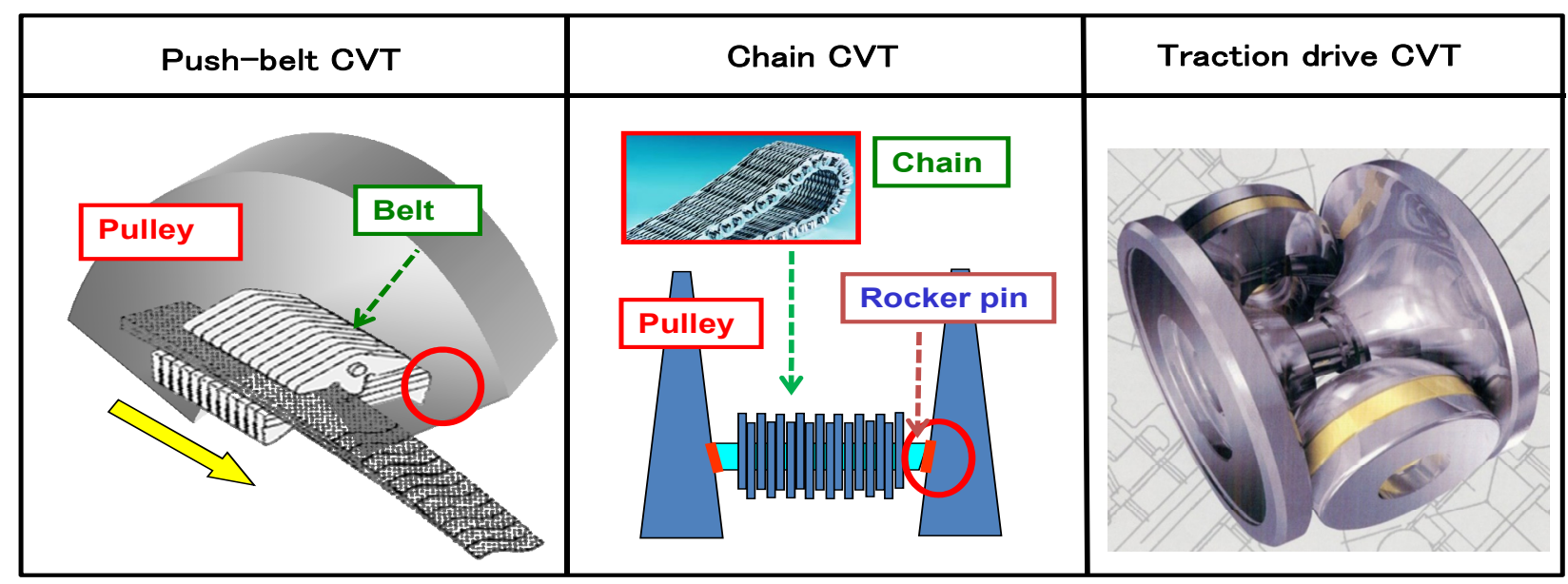

A metal push-belt CVT consists of a steel belt made up of about 400 elements and laminated rings. Power is transmitted by the frictional force generated between the belt and pulley. In a chain CVT, the power is transmitted by the friction generated between the chain rocker pin and pulley. There are also cases in which these two different types are combined and classified as a belt CVT. In order to improve transmission efficiency and spread the application of CVTs to larger cars, belt CVT lubrication fluids (B-CVTFs) must be able to produce a higher torque capacity between the belt and pulley. Likewise, it is known that a higher friction coefficient between the metal-metal contacting portions and the formation of stable lubricant films are essential to improving torque capacity [2,3]. For example, the films generated by zinc dithiophosphate (ZnDTP) additives in the contact regions are known to contribute to achieving a higher metal-metal friction coefficient [3]. ZnDTP tribofilms do not develop in rolling contact or if the hydrodynamic film thickness is significantly greater than the surface roughness [4]. Organic compounds around $100 \mathrm{~nm}$ thick are considered to comprise a glassy phosphate, which is closely associated with anti-wear performance [5]. It has been also reported that ZnDTP films may form pad-like structure consisting of glassy phosphate with an outer layer of $\mathrm{Zn}$ polyphosphate of $10 \mathrm{~nm}$ thickness [6,7]. Friction-velocity characteristics of oil containing ZnDTP and analysis of their tribofilms were reported [8].

As shown in Figure 2, B-CVTFs are made up of a base stock, a viscosity index improver, and various additives. The lubrication condition between the belt and pulley, the area which is the power transmitting portion of the CVT, is considered to be in the mixed/boundary lubrication regime. It is assumed that the friction coefficient is dependent on the shearing force based on the characteristics of the boundary lubrication film formed by the additives and the EHL (elastohydrodynamic lubrication) film. The authors reported the effect of lubricant additives in B-CVTFs exert on the friction properties between the metals $[9,10]$, and the effect of base stocks on the actual CVT transmission torque capacity [11]. This report reviews the results obtained from these studies. 
Figure 2. Composition of belt CVT lubrication fluids (B-CVTFs).

\begin{tabular}{|c|c|c|}
\hline Base stock & Antioxidant & Anti-wear additive \\
\hline \multirow[t]{3}{*}{ Viscosity index improver } & Corrosion inhibitor & Metal detergent \\
\hline & Defoaming agent & Dispersant \\
\hline & Friction modifier & \\
\hline
\end{tabular}

\section{Effect of CVT Lubricant Additives on the Metal-Metal Friction Characteristics}

\subsection{Test Method for Evaluating the Friction Characteristics between Metals}

When examining an actual belt CVT, the relative sliding between the belt and pulley, which is the area that serves as the power transmission portion, gradually increases as the input torque increases. However, once the input torque reaches a certain level, it becomes impossible to transmit power above that level. This input torque is defined as a transmittable torque capacity [12], and it is dependent on the clamping force on the pulley and the friction characteristics between the belt and pulley. Some friction test methods to reproduce the friction characteristics of an actual belt CVT in the laboratory have been proposed [2,3]. Figure 3 shows a block on ring type friction tester evaluating the friction characteristics between metals [9]. This test procedure is based on JASO M358 High load condition [13] and has been previously shown to be a valid method of assessing the torque capacity in a CVT between a candidate oil and a reference oil.

Figure 3. Block on ring type friction tester (Falex LFW-1).

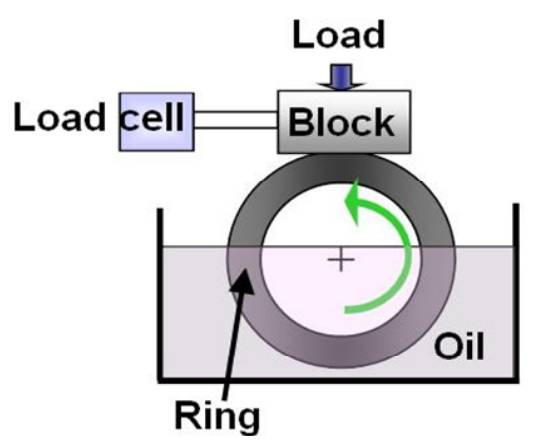

Test condition (JASO M358 High load)

\begin{tabular}{|l|l|l|}
\hline \multirow{2}{*}{$\begin{array}{l}\text { Test } \\
\text { specimens }\end{array}$} & Ring & $\mathrm{S} 10$ \\
\cline { 2 - 3 } & Block & $\mathrm{H} 60$ \\
\hline Load, $\mathrm{N}$ & 1112 \\
\hline Pressure $\left(\mathrm{P}_{\text {max }}\right), \mathrm{GPa}$ & 0.6 \\
\hline Speed, $\mathrm{m} / \mathrm{s}$ & $0.025-1.0$ \\
\hline Oil temperature, ${ }^{\circ} \mathrm{C}$ & 110 \\
\hline
\end{tabular}

In addition, B-CVTFs must also work with the other lubricated parts. For instance, in the CVT unit the gears transmit the power from the output pulley to the axle shaft, and the bearings are used to support the pulley shafts. Along with the higher friction between the metals, an anti-seizer property of the oil solution is also important because the contact pressure of lubricated parts, such as the gears and bearings, is estimated to be higher than between the belt and pulley. Figure 4 shows a pin on V block type friction tester evaluating the anti-seizer property [10]. With the pin revolving at a constant speed $(0.0096 \mathrm{~m} / \mathrm{s})$, the load added to the $\mathrm{V}$ block is gradually increased until it reaches the maximum level of $10,000 \mathrm{~N}$. The friction force is monitored while the load was being increased, and the load at which the friction force suddenly increased is deemed to be a seizer load. This test implies that using a greater load results in a better anti-seizer property for the test oils. 
Figure 4. Pin on V block type friction tester.
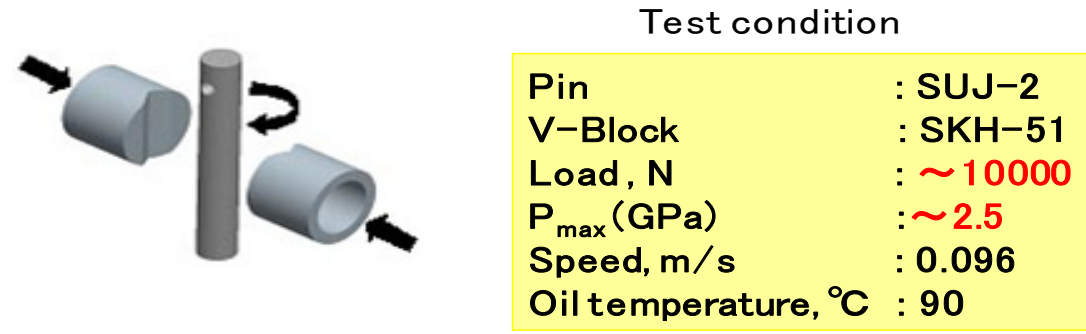

\subsection{Evaluation Results of Metal-Metal Friction Characteristics Tested by LFW-1}

Figure 5 shows the metal-metal friction characteristics tested by LFW-1 [9]. Table 1 shows the compositions of the test oils. Phosphorus additive as an anti-wear agent was added at the same concentration of 0.06 mass $\%$ into all tested oils. Calcium detergent and dispersant are blended in all samples. These additives are normally used in CVTFs in order to keep the transmission clean and also known to play an important role in controlling friction-velocity performance in lock-up clutch [9]. Friction modifier A and B were added into oil B and C. First, oil A shows the highest friction level of all tested oils. Oil B with friction modifier (FM) A demonstrated the almost same friction level as oil A. In the case of oil C containing FM B, there was $24 \%$ decrease in friction coefficient at $1.0 \mathrm{~m} / \mathrm{s}$ compared with oil A.

Figure 5. Metal-metal friction characteristics of test oils.

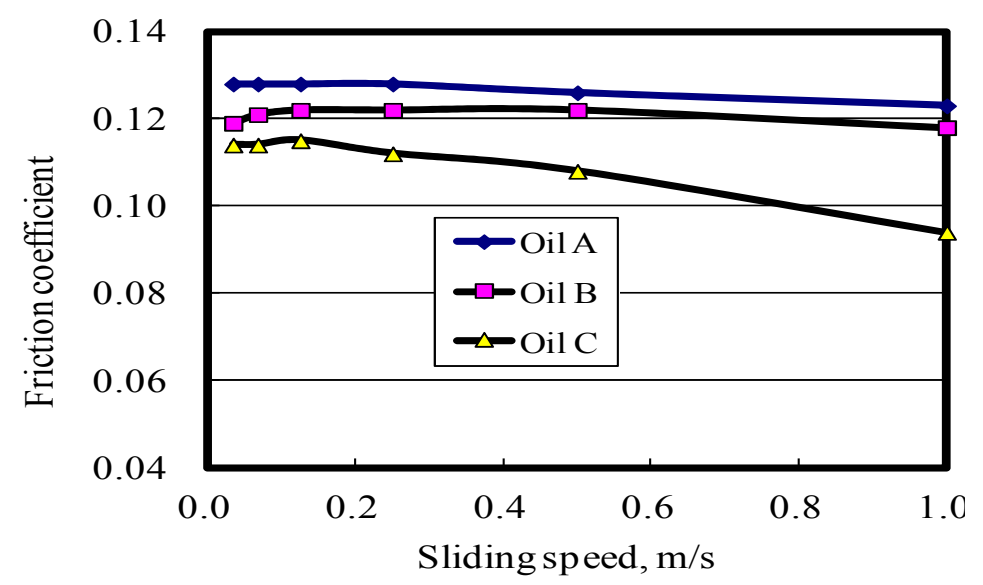

Table 1. Composition of test oils.

\begin{tabular}{lccc}
\hline & Oil A & Oil B & Oil C \\
\hline Phosphorus additive & $\sqrt{ }$ & $\sqrt{ }$ & $\sqrt{ }$ \\
Calcium detergent & $\sqrt{ }$ & $\sqrt{ }$ & $\sqrt{ }$ \\
Dispersant & $\sqrt{ }$ & $\sqrt{ }$ & $\sqrt{ }$ \\
Friction modifier A & & $\sqrt{ }$ & \\
Friction modifier B & & & $\sqrt{ }$ \\
Ca (mass\%) & 0.06 & 0.06 & 0.06 \\
P (mass\%) & 0.06 & 0.06 & 0.06 \\
B (mass\%) & 0.01 & 0.01 & 0.01 \\
Viscosity $\left(\mathrm{mm}^{2} / \mathrm{s} 100^{\circ} \mathrm{C}\right)$ & 7.1 & 7.1 & 7.1 \\
\hline
\end{tabular}


Figure 6 illustrates the contact force Atomic Force Microscopy (AFM) topographic images of the post-test blocks derived from the tested oils [9]. Note that the brighter parts in the AFM images represent higher positions on the surface. Very interestingly, the post-test surface with oil A exhibits clearly dense depositions having 1-5 $\mu \mathrm{m}$ elongated in the sliding direction. Furthermore, highly dense depositions can be observed on the wear scar from oil B. However, the surface from oil C does not possess distinct depositions. In addition, the ridges exist in the central part of wear track and the sides are polished, which might be due to the lack of tribofilm formation on the surface. Taylor and Spikes [14] showed that the ZnDTP reaction film appears to inhibit lubricant entrainment into the contact, thereby leading to a reduced elastohydrodynamic lubrication (EHL) film thickness compared with ZnDTP-free lubricants. It is hypothesized that the thicker and dense tribofilm derived from oil A and B plays a role in preventing wear and inhibiting the entrainment of lubricant into the interface, resulting in a higher friction. These results suggest that the frictional behavior strongly depends on the local morphology of the tribofilms from lubricant additives.

Figure 6. Atomic Force Microscopy (AFM) images of the post-test block by LFW-1.

\begin{tabular}{|c|c|c|}
\hline Oil A : Higher friction & Oil B : Higher friction & Oil C : Lower friction \\
\hline Wext & Fine depositions & ished \\
\hline
\end{tabular}

\subsection{Evaluation of Anti-Seizure Properties by Pin on V Block Test}

The test oils shown in Table 2 were prepared to investigate the effects of additives used in CVTFs on anti-seizure properties, such as anti-wear additive, metal detergent, dispersant and extreme pressure agent [10]. In oil I, only the effect of phosphorus anti-wear additive was evaluated, and oil II, the combined effect of phosphorus additive and calcium detergent was evaluated. For oil III, a dispersant was added to oil II. In order to improve an anti-seizure property, oil IV contained together with a sulfur-phosphorus extreme pressure agent, therefore, phosphorus and sulfur levels have increased in oil IV. Figure 7 indicates the results of the pin on V block friction test [10]. In the test that was conducted on oil I, the friction coefficient increased suddenly and seizure occurred when the load reached $7000 \mathrm{~N}$. Oil II and oil III exhibited the same seizure load, which was approximately $9000 \mathrm{~N}$. For oil IV, in which a sulfur-phosphorus extreme pressure agent was mixed, no seizure occurred even when the load exceeded $10,000 \mathrm{~N}$, and among the oils evaluated it exhibited the best anti-seizure results. When oil IV was used as test oil, the tests were stopped at test loads of 2500, 4000, and 10,000 N. 
Table 2. Composition of test oils.

\begin{tabular}{lcccc}
\hline & Oil I & Oil II & Oil III & Oil IV \\
\hline Phosphorus anti-wear additive & $\circ$ & $\circ$ & $\circ$ & $\circ$ \\
Calcium detergent & & $\circ$ & $\circ$ & $\circ$ \\
Dispersant & & & $\circ$ & $\circ$ \\
Sulfur-phosphorus extreme pressure agent & & & & $\circ$ \\
$100{ }^{\circ} \mathrm{C}$ viscosity $\left(\mathrm{mm}^{2} / \mathrm{s}\right)$ & 7.0 & 7.0 & 7.0 & 7.0 \\
Phosphorus (mass\%) & 0.02 & 0.02 & 0.02 & 0.03 \\
Sulfur (mass\%) & 0.03 & 0.03 & 0.03 & 0.04 \\
Calcium (mass\%) & - & 0.03 & 0.03 & 0.03 \\
\hline
\end{tabular}

Figure 7. Results of pin on block friction test.

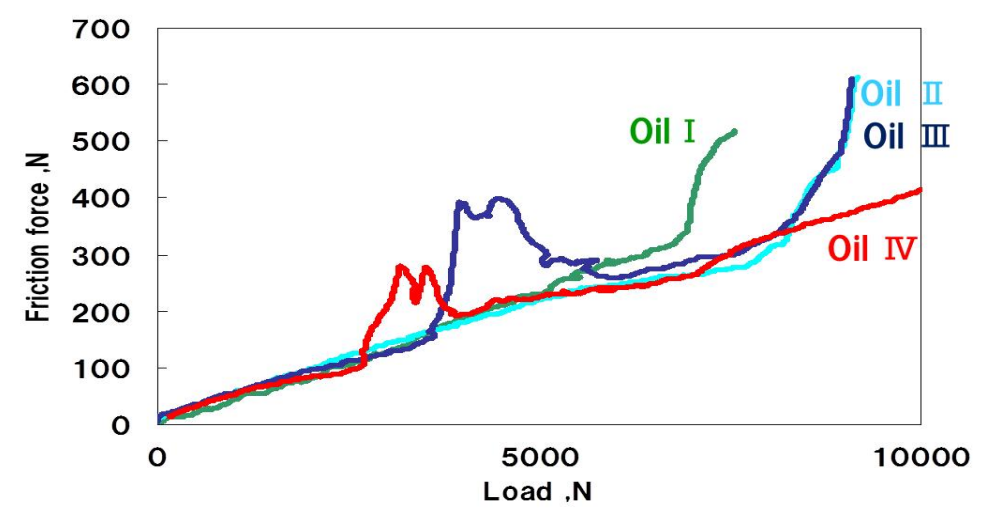

Figure 8 shows the results of electron probe micro analysis (EPMA) on each respective surface of the $\mathrm{V}$ blocks after the tests [10]. At a load of $2500 \mathrm{~N}$, there is a large amount of phosphorus (P) and oxygen $(\mathrm{O})$ elements distributed on the friction surface. In addition to phosphorus and oxygen, when the load is increased to $4000 \mathrm{~N}$, the ratio of sulfur elements also increases. When the surfaces were examined after the $10,000 \mathrm{~N}$ test, the distribution of sulfur becomes even more significant. The above results demonstrate that when a sulfur-phosphorus extreme pressure agent is subjected to higher load conditions, the sulfur acts on the friction surface and produces a protective film, thereby indicating the anti-seizure property has been improved.

\section{Effect of Base Stock on the Torque Capacity of Belt CVT Transmissions}

As mentioned above, it is found that the boundary film characteristics of additives exert a major effect on the friction characteristics between the metals in B-CVTs. An American Petroleum Institute (API) group 2 oil, group 3 oil, or a synthetic oil polyalphaolefin (PAO) is generally used as CVTF base oil in order to maintain fluidity within an extremely low temperature environment of $-40{ }^{\circ} \mathrm{C}$ or below. In the traction drive CVT (T-CVT) describes in Figure 1, power is transmitted by the shearing force of the EHL oil film resulting from rolling and sliding lubrication condition that occurs between the disk and rollers. For the T-CVTF base stock, synthetic naphthene (SN) is used because of superior traction characteristics (high oil-film shearing force) under a high pressure of $1 \mathrm{GPa}$ or greater. Likewise, because relative sliding between the belt and pulley occurs, there is also a possibility of the oil-film shearing force contributing to the generation of transmission torque in belt CVTs. Narita and 
Tamoto [11] reported the effect of the base stock on the transmission torque capacity by using an actual belt CVT tester. The summary obtained from this study is described in the following section.

Figure 8. Results of electron probe micro analysis (EPMA) analysis on the post-test V block.

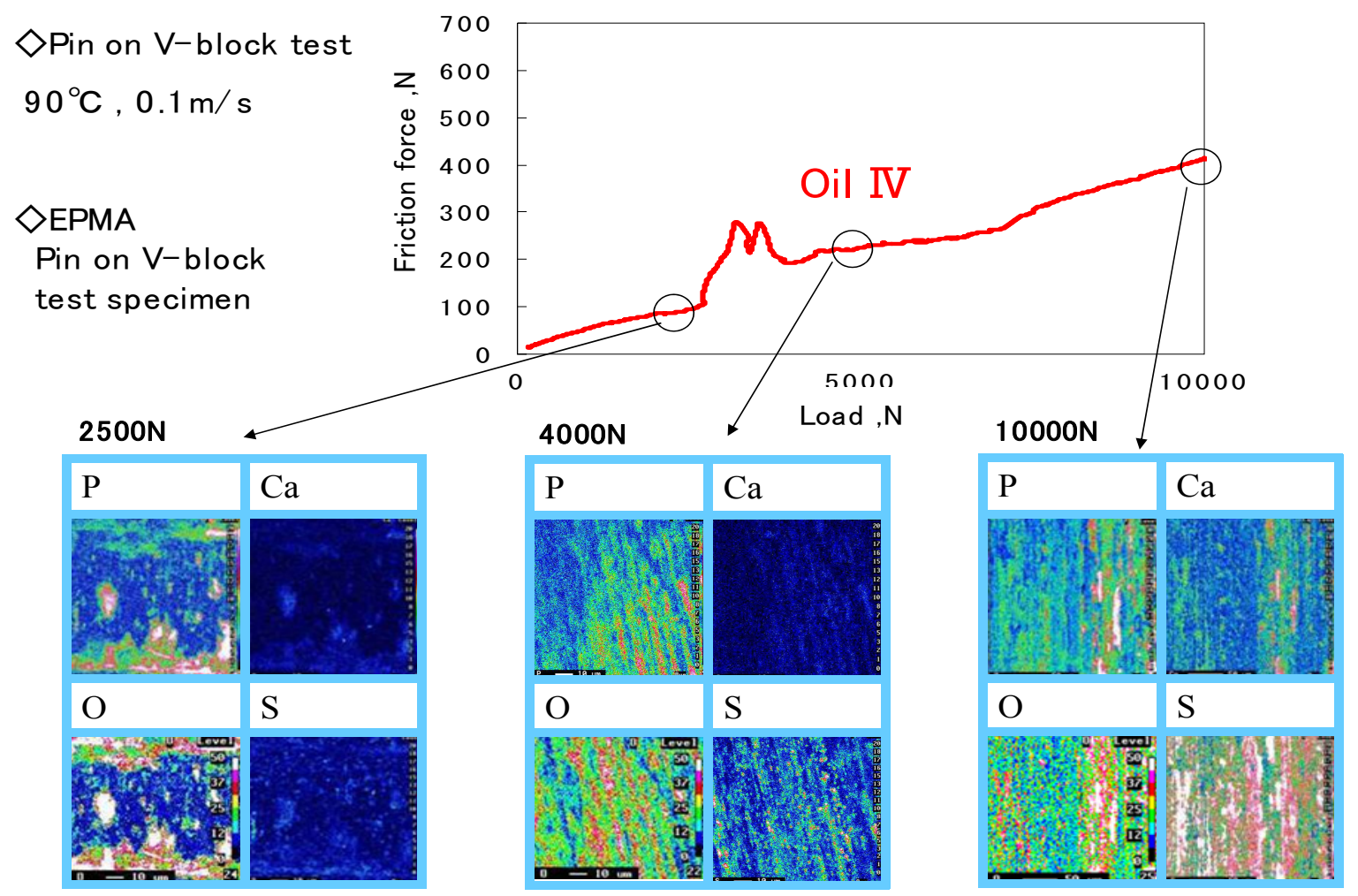

\section{Evaluation of Transmission Torque Capacity Using an Actual Belt CVT}

Figure 9 shows the maximum transmittable torque capacity of an actual belt CVT test rig that was used. Polyalphaolefin (PAO) and SN were used as the test oils, and the clamping force of the output pulley was changed from 17 to $34 \mathrm{kN}$ at a constant oil temperature of $100{ }^{\circ} \mathrm{C}$, with the input pulley speed at $14 \mathrm{~m} / \mathrm{s}$ [11]. As illustrated by the figure, the torque capacity ratio for SN, which has a torque capacity of $34 \mathrm{kN}$, was 1 . Furthermore, this result focused on the rheological characteristics of the base stocks, since a viscosity index improver was not added to the test oils. With regards to the additive formulation, a phosphorus additive and a calcium detergent were added to the test oils in order to prevent seizures from occurring between the belt and pulley. It is evident that for both test oils the increase in the pulley clamping force causes the torque capacity to increase. In a comparison of the two test oils, SN exhibits a 10\% higher torque capacity than PAO. The lubrication conditions between the belt and pulley in the CVT seem to be mainly in the boundary lubrication regime. When SN is used as the B-CVTF base stock, the effect of the oil-film shearing force cannot be neglected. As shown in Figure 9, when the clamping force on the pulley is $25 \mathrm{kN}$, the contacting pressure between the belt and pulley in the active arc area of the smaller diameter side pulley is calculated to be $400 \mathrm{MPa}$ [11]. 
Figure 9. Effect of base stock on the transmission torque capacity of actual belt CVTs.

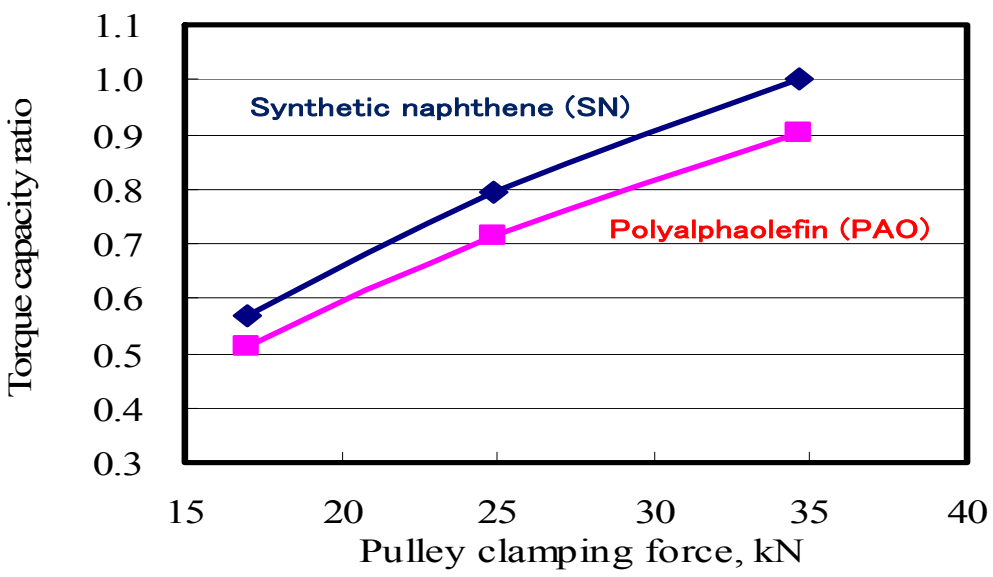

The high speed four cylinder rolling and sliding friction tester shown in Figure 10 was used to examine the traction coefficients (oil-film shearing force/normal load) of SN and PAO at a rolling speed of $15 \mathrm{~m} / \mathrm{s}$, a constant pressure $\mathrm{P}_{\max }$ of $400 \mathrm{MPa}$, and an oil temperature $100{ }^{\circ} \mathrm{C}$ [11]. The result obtained from this tester is shown in Figure 11 [11]. For SN, the traction coefficient exhibits a non-linear increase as the sliding ratio rises (up to 5\%). According to calculation, in this friction test the relative sliding between the actual CVT belt and pulley corresponds to a sliding ratio of $2 \%-3 \%$. Therefore, the rheological characteristics of the belt and pulley are in the non-linear region. Although SN exhibited a high traction coefficient, no clear increase in traction coefficient could be observed for PAO. Based on these results, it can be assumed that the difference in the oil-film shearing force was generated by relative sliding between the belt and pulley. When SN is used as base stock, it is found to exhibits a torque capacity $10 \%$ higher than PAO as a result of its high oil-film shearing force.

Figure 10. High speed four cylinder rolling and sliding friction tester.

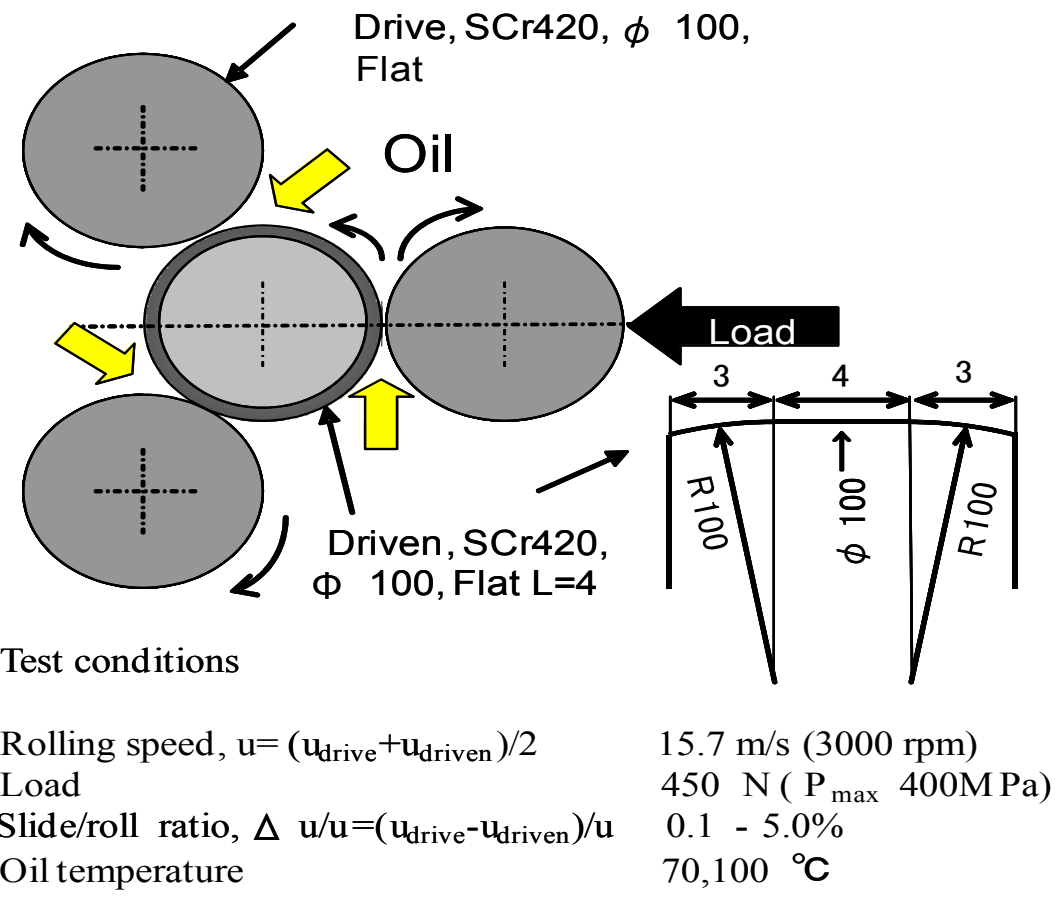


Figure 11. Effect of base stock on traction coefficient.

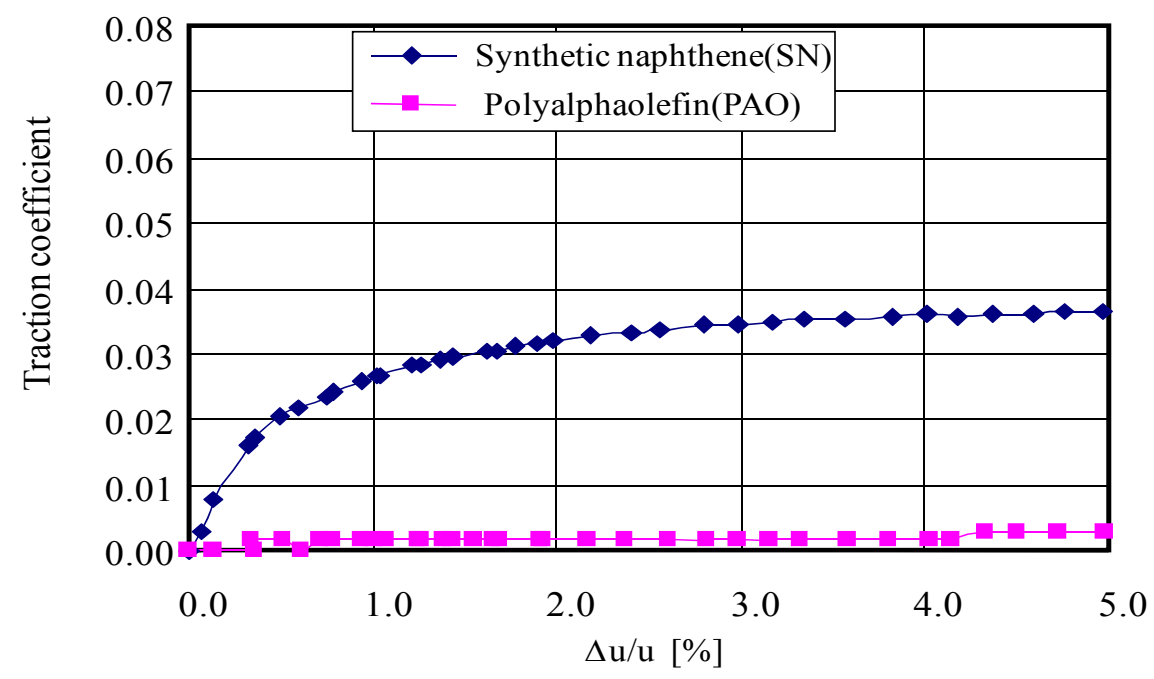

\section{Conclusions}

This paper describes the effect that the additives and base stock used in the metal belt type CVT lubricant have on the CVT transmission torque capacity. The summary is as follows:

(1) An additive formulation consisting of a combination of a phosphorus anti-wear additive, a calcium detergent improves the friction coefficient between the metals. The post-test surface derived from these additives exhibits clearly dense depositions. Because this film is rougher, it is assumed there is a higher friction coefficient. By further adding a sulfur-phosphorus extreme pressure agent, it will be possible to improve anti-seizure properties while maintaining a higher friction coefficient.

(2) Examining the effect of base stock on the transmission torque capacity of actual belt CVTs revealed that SN (synthetic naphthene) exhibited a 10\% higher torque capacity than that of PAO (polyalphaolefin). It is believed that the difference in the oil-film shearing force was generated by the relative sliding between the belt and pulley.

The above results indicate that lubrication oil greatly affected the performance of belt CVTs. In addition to analyzing the chemical composition and state of lubrication oil film, it is believed that friction mechanisms which were previously unknown can be now clarified by applying the information obtained from the nano-level physical properties of the films.

\section{Conflicts of Interest}

The authors declare no conflict of interest.

\section{References}

1. Murakami, Y. Half a century of automatic transmissions for vehicles. Jpn. Soc. Tribol. 2005, 50, 665-670.

2. Mitsui, H. Trends and requirements of fluids for metal pushing belt type CVTs. J. Jpn. Soc. Tribol. 2000, 45, 13-18. 
3. Ishikawa, T.; Murakami, Y.; Yauchibara, R.; Sano, A. The effect of belt drive CVT fluid on the friction coefficient between metal components. SAE Trans. 1997, 106, 1290-1297.

4. Fijita, H.; Spikes, H.A. The formation of zinc dithiophosphate antiwear film. Proc. Inst. Mech. Eng. 2004, 218, 265-277.

5. Bec, S.; Tonk, A.; George, J.M.; Coy, R.C.; Bell, J.C.; Roper, G.W. Relationship between mechanical properties and structures of zinc dithiophosphate anti-wear films. Proc. R. Soc. Lond. 1999, 455, 4181-4203.

6. Yin, Z.; Karsai, M.; Fuller, M.; Bancroft, G.M.; Fyfe, K.; Colainanni, M.L.; Tan, K.H. Application of soft X-ray absorption spectroscopy in chemical characterization of antiwear films generated by ZDDP Part I: The effects of physical parameters. Wear 1997, 202, 172-191.

7. Martin, J.M.; Grossiord, C.; Monge, T.L.; Bec, S.; Tonck, A. The two-layer structure of Zndtp tribofilms: Part 1: AES, XPS and XANES analysis. Tribol. Int. 2001, 34, 523-530.

8. Muraki, M.; Oshima, A. Friction-velocity characteristics of oils containing ZDDP and analysis of their tribofilms. J. Jpn. Soc. Tribol. 2011, 56, 523-529.

9. Narita, K.; Iwai, T.; Takekawa, D. Lubricants additives for improving the performance of metal V-belt type CVTs. Tribol. Online 2012, 7, 152-158.

10. Narita, K.; Iwai, T. Study on the use of metal belt CVT lubricant to improve transmission torque capacity. Idemitsu Tribol. Rev. 2011, 33, 2080-2086.

11. Narita, K.; Tamoto, Y. Effect of Lubricating Base Stocks on the Transmittable Torque Capacity of Metal V-Belt Pushing Type CVT. In Proceedings of the JSME International Conference on Motion and Transmissions, Sendai, Japan, 13 May 2009; pp. 614-619.

12. Fewkes, R.; Gunsing, J.; Sumiejski, J.L. Lubricants as construction element in the VDT push-belt CVT system. SAE Paper 1993, doi:10.4271/932848.

13. Japanese Automobile Standard Organization M358-2005. Standard Test Method for Metal Friction Characteristics of Belt CVT Fluids; JASO: Tokyo, Japan, 2005.

14. Taylor, L.; Spikes, H.A. Friction-enhancing properties of ZDDP anti-wear additives: Part 1-Friction morphology of ZDDP reaction films. Tribol. Trans. 2003, 46, 303-309.

(C) 2014 by the authors; licensee MDPI, Basel, Switzerland. This article is an open access article distributed under the terms and conditions of the Creative Commons Attribution license (http://creativecommons.org/licenses/by/3.0/). 